\title{
Colite isquêmica como hipótese diagnóstica em quadro de abdome agudo - Relato de caso
}

\author{
Izabela de Magalhães Trindade'; Larissa Reginato Junges²; \\ Marcella Frazzon Fruet ${ }^{3}$; Aldomar Renato Pederiva Filho ${ }^{4}$
}

\section{Resumo}

INTRODUÇÃO: A colite isquêmica (CI) constitui a causa mais comum de isquemia do aparelho gastrointestinal e ocorre devido a irrigação inadequada na parede cólica com hipoperfusão local e hipóxia tecidual. Acomete mais a população idosa e observa-se taxas de mortalidade superiores a 50\%. Este trabalho tem como objetivo ressaltar a importância de diagnósticos diferenciais para que o manejo adequado da doença seja feito de forma precoce em atendimentos emergenciais. RELATO: S.M.S., feminina, 76 anos, caucasiana, procedente de Santo Antônio das Missões/RS. A paciente procurou o Pronto Socorro (PS) no dia 21 de Julho de 2015 devido à síncope após episódio de dor abdominal em cólica e vômito. Chegou ao PS com pressão inaudível, descorada e mal perfundida. Recebeu 1,5L de soro fisiológico e apresentou melhora do quadro. Durante a internação teve diarreia sem sangue, pus ou muco. A equipe médica apontou gastroenterite ou diverticulite como possíveis diagnósticos. A ultrassonografia abdominal apresentou ascite pequena com infiltrado em alças. $\mathrm{O}$ exame de tomografia

\footnotetext{
Graduanda de Medicina da Universidade Luterana do Brasil - ULBRA. belatrindade@hotmail.com

${ }^{2}$ Graduanda de Medicina da Universidade Luterana do Brasil - ULBRA. lari.junges@gmail.com

${ }^{3}$ Graduanda de Medicina da Universidade Luterana do Brasil - ULBRA. cellafrazzon@gmail.com

${ }^{4}$ Médico Gastroenterologista do Hospital Ivan Goulart - São Borja/RS. arpederiva@bol.com.br
} 
computadorizada mostrou espessamento das paredes ao longo do cólon descendente. Já em tratamento com antibiótico, a paciente ainda apresentava forte dor abdominal referida em fossa ilíaca esquerda sem sinais de peritonismo. Foi realizado colonoscopia com biópsia, que sugeriu presença de mucosa enantematosa, edematosa, friável, com espessa camada de fibrina cujo o exame anatomopatológico indicou inflamação fibrinosa aguda e crônica ulcerada de mucosa do intestino grosso, com focos de necrose, confirmando o diagnóstico de CI. DISCUSSÃO: Em quadros de abdome agudo, todo paciente idoso atendido com diarreia, cólica abdominal e vômito, antes de ser diagnosticado como gastroenterocolite aguda (GECA) ou como doença inflamatória intestinal inespecífica, deve ser investigado como possível portador de CI. Reconhecê-la é fundamental uma vez que ela supera, em número, a trombose e a embolia mesentérica nos casos de abdome agudo. O diagnóstico da $\mathrm{CI}$ depende da consideração dos elementos da história clínica, da evolução, dos achados em exames de imagem, da forma e da fase da doença, o que torna importante incluí-la entre as hipóteses diagnósticas, já que não há um aspecto patognomônico de CI. 
